\title{
A Computational Framework for Estimating the Carbon Footprint of Construction
}

\author{
Z.S. Moussavi Nadoushani ${ }^{a}$ and A. Akbarnezhad ${ }^{a}$ \\ ${ }^{a}$ School of Civil and Environmental Engineering, University of New South Wales, Australia \\ E-mail: z.moussavinadoushani@student.unsw.edu.au, a.akbarnezhad@unsw.edu.au
}

\begin{abstract}
-
Estimation of the carbon emissions in the construction phase of the building life cycle requires acquiring and analysing a great deal of project specific data including the amount of the works performed by different equipment and the unit emissions of various machinery at different work conditions. Such information are very project specific and vary from one stage of the construction phase to another. Building Information Models (BIM) have been proposed as efficient sources of information which can be utilized to computerize the construction carbon estimation. However, an easyto-use methodology and framework to perform such analysis is still lacking. In this paper, a BIM-based framework is proposed to estimate the construction carbon emissions using the quantity take-offs from BIM and the information obtained from WBS and carbon inventories. The proposed method also includes a predefined simulated construction process for various types of buildings which can be used to estimate the carbon emissions when construction plans are not available. Therefore, the method proposed in this paper can be used to compare carbon emissions of the various potential designs at early stages of the building design. A case study is presented to illustrate the advantages of the proposed framework.

Keywords -

$\mathrm{CO}_{2}$ emission, Construction stage, Automation, BIM, Quantity takeoffs
\end{abstract}

\section{Introduction}

According to the Fourth Assessment Report of the Intergovernmental Panelon Climate Change (IPCC), the building and construction sector is one of the seven dominant sectors that greatly contribute toward global greenhouse gas (GHG) emissions [1]. The building and construction industry consumes up to $40 \%$ of total worldwide used energy, and contributes up to $30 \%$ to the total GHG emissions annually. The United Nations
Environment Programme (UNEP) estimates show that as a result of the sharp surge in urbanization and the inefficiency of existing building stock, GHG emissions will more than double in the next 20 years unless preventive measures are taken [2].

The total energy and GHG emissions of buildings constitute all those incurred in various phases of the building life cycle including the construction, use and end of life phases. In general, the life cycle emissions of buildings may be divided into two groups; embodied and operational. Embodied carbon (EC) refers to all primary carbon emissions associated with the energy used, directly or indirectly, throughout the life-cycle of a building component; and operating carbon (OC) which is emitted in maintaining the inside environment through processes such as heating and cooling, lighting and operating appliances. With this definition, the embodied carbon may include the carbon emitted by production and transportation of building components and by construction operations. The carbon emitted during production and transportation of building components is referred to as cradle to site embodied carbon. The available literature on reducing the embodied carbon of buildings is mainly focused on reducing the cradle to site embodied carbon of buildings through selection and use of low carbon materials. Significantly less has been done to investigate various methods to reduce the carbon emissions incurred in the construction and end of life phases of building life cycle. With achievements in reducing the operational energy of buildings and growing hopes for making net zero energy buildings dream a reality, the relative share of the embodied energy and its associated GHG emissions in the life cycle carbon of buildings tend to increase. Therefore, estimating the total embodied carbon of buildings including the carbon emissions incurred in the construction phase has attracted a great deal of attention and is the topic of worldwide research.

However, estimation of the carbon emissions in the construction phase of the building life cycle requires acquiring and analysing a great deal of project specific data including the amount of the works performed by different equipment and the unit emissions of various 
machinery at different work conditions. Such information are very project specific and even vary from one stage of the construction phase to another, rendering the analysis difficult and time consuming using traditional estimation techniques. The lack of a computational tool and the complexity of the construction stage highlight the need for an automation framework to enable the early estimation of the GHG emissions of this stage. A number of computing methods based on building information modelling and 4D modelling of buildings have been proposed to improve the estimation precision and reduce the computational time of the construction carbon estimations. However, an easy-to-use methodology and framework that considers all influencing parameters including the specific construction requirements of different construction components, emissions of individual construction operations, distance between the construction site and different material/component processing/fabrication sites and, the availability of equipment is lacking. In addition, all previously proposed computerized estimation methods require a great deal of details related to the availability of resources and construction plans and thus are of little value during the design stage of buildings when such details may not be yet available. In this paper, a BIMbased framework is proposed to estimate the construction carbon emissions using the quantity takeoffs from BIM and the information obtained from WBS and carbon inventories. The proposed method uses the simulated construction process for various types of buildings to estimate the carbon emissions when construction plans are not available. Therefore, the method proposed in this paper can be used to compare the carbon emissions of the various design and construction method alternatives at early stages of planning. A hypothetical example is presented to show the applicability of the proposed framework.

\section{Available Methods for Estimating the Carbon Footprint of Construction}

Estimation of carbon emission of construction has attracted a great deal of attention in the past two decades. The study conducted by Cole (1998) [3] was one of the first attempts to estimate the energy and greenhouse gas emissions associated with the construction of alternative structural systems. In this study, a detailed examination of the energy and greenhouse gas emissions associated with the on-site construction of a selection of alternative wood, steel and concrete structural building assemblies was performed to investigate the share of the construction process in the total initial embodied carbon and the effects of different structural alternatives on the latter. Results of this study showed considerable differences between the GHG emissions associated with construction of alternative wood, steel and concrete structural assemblies and highlighted the construction of the concrete assemblies as the highest GHG emitter. The largest proportion of construction energy use for most structural assemblies was reported to be associated with the transportation of workers to and from the construction site [3].

Guggemos and Horvath [4, 5] developed a Construction Environmental Decision-Support Tool (CEDST) to evaluate the environmental effects due to the construction of commercial buildings. CEDST follows a predefined detailed process diagrams [5] to quantify the energy use and carbon emissions of the construction stage based on the designer's and builder's choices of structural materials, temporary materials and employed equipment. Through a case study, they showed that a single decision such as using a concrete mixer truck with a $335 \mathrm{hp}$ engine rather than a $565 \mathrm{hp}$ engine (with the same capacity) can reduce the total construction energy demand by as much as $12 \%$. This highlights the importance of availability of a computerized carbon estimation tool to evaluate the effect of various decisions on the carbon emissions in construction and thus embodied carbon of the building.

The increasing interest on evaluating and comparing the environmental impacts of different construction scenarios led to several studies aimed at developing methods for quantitative estimation of the energy usage and GHG emissions in the construction phase. Yan et al. [6] and Mao et al. [7] evaluated the GHG emissions and energy consumption of the construction phase by considering different sources of emission (different boundaries). Unlike the previous studies [3, 4, 5], in these studies the embodied energy of the permanent building component's materials was considered as a part of the construction embodied energy. However, one of the drawbacks of such methods is the considerable amount of information required to perform the analysis. This information includes the amount of the fuel, electricity, water and various materials used by different contractors. Therefore, such methods are not applicable to predict the carbon emissions before the completion of an actual construction activity. The need for the availability of actual site data is also a limiting factor in a number of other proposed frameworks including that proposed by Wong et al. [9]. The framework proposed by Wong et al. [9] uses a wide range of data collected on the needed equipment and their respective fuel consumptions as well as planned activity durations and start and finish times to estimate the construction related emissions incurred in a specific period of time. The latter is then combined by a virtual prototyping tool to allow the project teams to visualise the predicted carbon 
emissions at different times in the construction process. To eliminate the dependence on fuel consumption data, Hong et al. [8] proposed a model to assess the energy consumption and GHG emissions in the construction phase by reflecting the type and energy efficiency of the equipment needed, based on the amount of the materials used and characteristics of the building project and construction site.

While the models developed in the previous studies reviewed above can be applied to achieve relatively satisfactory estimates of carbon emissions during construction, such methods have a number of disadvantages. First, the data entry requirements for the user are quite extensive, rendering the developed methods unsuitable for application in the early design stages. Second, quantity take-off and analysis of the collected information using traditional estimating methods are time consuming. The investors are inherently reluctant to spend money and time to perform carbon estimation of various construction alternatives, especially when reduction in carbon footprint is not an organizational or project objective. Third, while the carbon inventories for materials and activities are becoming more accessible, there is a lack of interoperability between design and analysis software and datasets that enable full life cycle analysis (LCA) of the building [10]. A number of computational based methods have recently been proposed to overcome or alleviate these problems. Russell-Smith and Lepech [10] proposed a framework to integrate BIM and LCA. The proposed framework uses the quantity take-offs from building information models and the unit carbon emissions of various materials and activities obtained from various data inventories to estimate the carbon emissions associated with the construction. However, feasibility and accuracy of the proposed method has not been yet investigated. Moreover, a major drawback of the method proposed by Russell-Smith and Lepech [10] is its inability to capture the effects of off-site and insite transportation. The transportation of equipment or material from the processing/fabrication sites to the construction site is responsible for a great deal of carbon emissions during the construction process. Transportation has been reported as the second dominant parameter in the embodied energy/carbon of buildings after materials manufacturing $[6,7,8]$. The LCI databases mainly report on the cradle to gate embodied carbon of materials which should be modified to include the transportation impact to obtain cradle to site embodied carbon. To achieve a more accurate estimate of carbon emissions during construction, there is a need to identify the transportation requirements of a particular project and the associated carbon emissions based on the mode of transportation and quantity of the materials to be transported both in-site and off-site.
In this paper, a comprehensive computational framework is proposed to eliminate some of the major drawbacks associated with the existing methods of construction carbon estimation. The proposed computational framework uses the quantity take-offs from BIM to estimate the amount of the work performed by each construction equipment and transportation vehicle by taking into account the project specific information available including the availability of equipment. The estimated work hours and user input information about likely locations of various material/component processing and prefabrication facilities are then used by an analyzer unit to estimate the construction carbon emission. The effects of both on-site and off-site transportation are considered by estimating the transportation requirements. The construction simulator module of the proposed framework and tool enables designers to obtain an estimate of the carbon emission of various construction and design alternatives in early design stages. The latter can be highly beneficial in decision making about selection of best project alternatives. In addition, when coupled with optimization tools, the proposed methodology can be used to optimize the construction process in order to minimize the carbon emissions of the project.

\section{Proposed Framework}

By considering the objectives outlined earlier, the main challenge in this study was to develop methods for estimating the quantity of the works performed and materials used using the limited information available at the early stages of design phase. We assume that the only resource available is a rough 3-D representation of building modelled and analyzed using a state-of-the-art building information modelling software. We also assume that the information on the construction methodology and sequence of operations to perform a specific job is not available at the time of the analysis. As shown in Figure 1, the proposed framework consists of four main modules: (1) data collection unit; (2) project database; (3) carbon database; (4) construction process simulator and carbon emission analyser. The following sections provide a brief explanation of each module. For simplicity, the framework and case study presented in this paper only consider the construction of the structural elements (foundation, columns, beams, slabs and walls). However, the concepts developed in this study are general and can be easily extended to include all construction activities. 


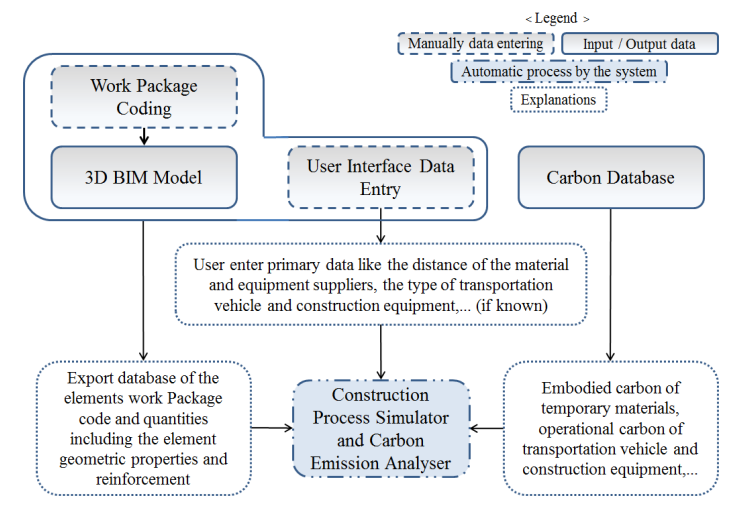

Figure 1. Flowchart of the proposed framework

\subsection{Data Collection Unit}

As mentioned earlier, this study assumes that the analysis is performed in the early stages of design when the actual construction data are not available at the time of the analysis. By taking this into consideration, the proposed framework uses the quantity take-offs from a customized Building information model (BIM) developed in any state-of-the-art software including Autodesk Revit or Tekla Structures. For instance, Autodesk Revit has a powerful schedule and quantity take-offs tool which can be used to collect geometric data and properties of the building elements including the material, element type, cast unit, etc. Revit also has built-in equations to calculate parameters such as volumes (volume $=$ length $\times$ width $\times$ height $)$ of various materials used. Another feature of most state-of-the-art BIM software is the possibility to add new attributes to the building elements. For instance, the "shared parameter" function in Revit can be used to add a specific property, which is not already available in the default property listing of the software, to the building elements. The framework proposed here makes use of this feature to perform basic calculations within the BIM environment rather than in an external processor. For instance, a built-in equation is defined for concrete structural elements to determine their perimeters which are then used to calculate the area of the formworks required. Moreover, a shared parameter named "PWP coding" is assigned to all structural elements to refer to their Predefined Work Packages. With this, any element family in Revit has a PWP code which determines the specific series of the activities required to construct the element. The PWP code is assigned to element families through predetermined formulas which use basic properties of the element to determine the construction method needed. The use of PWP as a built-in attribute can considerably reduce the computational time by eliminating the process which would have been otherwise performed by the external processor to identify the activities required to construct the element. Further details about the Predefined Work Packages are presented in the following sections.

The quantities of materials (including reinforcing steel, and concrete) required for erecting columns, beams, walls, and slabs are extracted and exported as separate .txt files which can then be imported by the data processor to create the data base required for the analysis.

\subsection{Project Database}

Project database comprises information imported from BIM as explained in the previous section as well as any project specific data available. Although the framework presented in this study requires minimal project specific information, the project database was programed to import any available actual project data including the equipment list, schedule or work breakdown structure (WBS) and modified construction procedures for particular element families (PWP codes). If available, this information will then replace the results of the simulation and the default values. To be imported to the project database, such information should be saved in the prescribed formats and stored in the prescribed file directory. The analyzer developed in the present study then searches for the specific file formats saved in the predefined directory, imports the required data from the files available and sorts them out into the data structure which could be later used by the processor to perform various calculations.

A user interface was developed to collect the user preferences where various alternatives to conduct a particular work are available. Many construction activities can be conducted using different combinations of equipment or methods. In such cases, a set of alternative options are generated based on the resource availability indicated in the project database and the user is asked to select the preferred options based on his/her engineering judgement. The options provided in our developed tool are related to the vehicle type, alternative suppliers of a material (or inputting the estimated travelling distance for critical materials) which can be selected from the embedded dropdown menus generated using the results of the construction process simulation.

\subsection{Carbon Database}

The carbon database consists of three sub-databases: (1) the "material" sub-database comprising embodied carbon factors for temporary materials used in the construction process; (2) the "transportation" subdatabase comprising carbon emission factors for 
different vehicles commonly used to transport materials, building components and equipment to and from construction site; (3) the "equipment" sub-database comprising carbon emission factors for different equipment used commonly in construction. The carbon database was developed using various international carbon inventories available $[12,13]$.

\subsection{Construction process simulator and carbon emission analyser}

The construction process simulator is a computer program developed in MATLAB which identifies the construction process (series of construction operations) required to construct a particular element in the building.

The program first identifies the general WBS for the construction of the particular building type by analysing the type of the individual elements in the building. For instance, the predefined WBS for the construction of a cast-in-place concrete building comprises the following tasks: hoisting and setting of column steel, setting of column forms, pouring the columns concrete, hoisting and setting of wall steel, setting of wall forms, pouring the walls concrete, hoisting and setting of beam steel, setting of beam forms, setting of slab forms, hoisting and setting of slab steel, pouring the beams and slabs concrete. If available at the time of the analysis, the actual WBS and/or schedules overwrite the predefined WBS. In the next step, the program uses the PWP attribute imported from BIM to identify the type and number of the construction operations required to complete one unit of a particular job (e.g. construction of a cast in-situ concrete column). The PWPs used in the present study were developed based on RSMeans [11]. Table 1 illustrates an example of a PWP for construction of cast-in-place concrete elements. It is worth mentioning that at this stage of the work only the tasks involving the use of special fuel consuming equipment or vehicle are considered. As a part of the future work, the labour requirements will be added to the PWPs to estimate emissions due to the transportation of labours to and from the construction site.

By considering the capacities and efficiencies of the required equipment available, the analyser uses the quantity take-offs from BIM to estimate the amount of the work performed by each construction equipment and transportation vehicle. The latter is then used to calculate the emitted carbon of the individual construction operations using the equations deduced from reference [8]. The emissions associated with individual operations are then summed up to calculate the total emissions associated with the predefined/given WBS.

\section{Case Study}

The proposed framework was adopted to predict the $\mathrm{CO}_{2}$ emissions due to the construction of a three story hypothetical building with a total area of $960 \mathrm{~m}^{2}$. The $3 \mathrm{D}$ view of the case structure comprising various structural elements (foundations, columns, walls, beams and slabs) is shown in Figure 2. The model was developed in Autodesk Revit. The travelling distance between the material processing sites and construction site was assumed to be $30 \mathrm{~km}$ for all the materials. With this simplifying assumption, the transportation emissions are estimated for round trips comprising of 30 $\mathrm{km}$ travel of loaded vehicles to the construction site and $30 \mathrm{~km}$ return travel of the unloaded vehicles to the processing plant or supplier's facility. These assumptions can be modified by the user through inputting travelling distance estimates manually or selecting the preferred suppliers from the list of local suppliers available in the project database. It was assumed that plywood formworks can be reused for a maximum of 3 cycles of casting. The overall work breakdown selected by the analyzer includes the use of crane and bucket for pouring concrete, two vibrators for vibrating the poured concrete and a truck crane to displace and hoist the forms and reinforcements.

Table 1. PWP for construction of a cast in-situ concrete element

\begin{tabular}{|c|c|}
\hline $\begin{array}{c}\text { Tasks included in Predefined Work } \\
\text { Package }\end{array}$ & Considered vehicles and equipment \\
\hline 1. hoisting and setting of steel & $\begin{array}{l}\text { 1.1. Transportation of steel bars to the construction site (truck...) } \\
\text { 1.2. Hoisting and setting the bars for each level (crane...) }\end{array}$ \\
\hline 2. setting of forms & $\begin{array}{l}\text { 2.1. the amount of used form } \\
\text { 2.2. Transportation of form to the construction site (truck...) } \\
\text { 2.2. Setting the form for each level (crane...) }\end{array}$ \\
\hline 3. pouring concrete & $\begin{array}{l}\text { 3.1. Transportation of concrete to the construction site (concrete mixer } \\
\text { truck) } \\
\text { 3.2. Pouring the concrete for each level (crane...) }\end{array}$ \\
\hline 4. vibration of concrete & 4.1. vibration of the poured concrete (vibrator) \\
\hline
\end{tabular}


Various stages of the analysis performed are shown in Figure 3. Figure $3 \mathrm{a}$ and $3 \mathrm{~b}$ show the project database units developed in MS Excel. The quantity take-offs from the building information model including the volumes of concrete and reinforcements as well as the geometrical properties of different elements were imported from the text files generated by Revit. As can be seen in Figure 3b, each structural element has a PWP attribute which refers to its element family and thus determines the chain of the operations required for its construction. The quantity of total reinforcements, concrete and formworks required as estimated by Revit is shown in Table 2.

After importing the quantities and the PWP codes to the project database, the analyzer program developed in MATLAB was run to simulate the construction operations and calculate the associated carbon emissions using the methodology presented in this paper.

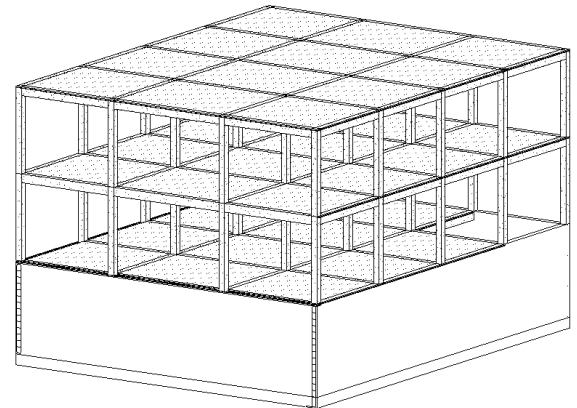

Figure 2. 3D view of the structural elements and their embedded reinforcement

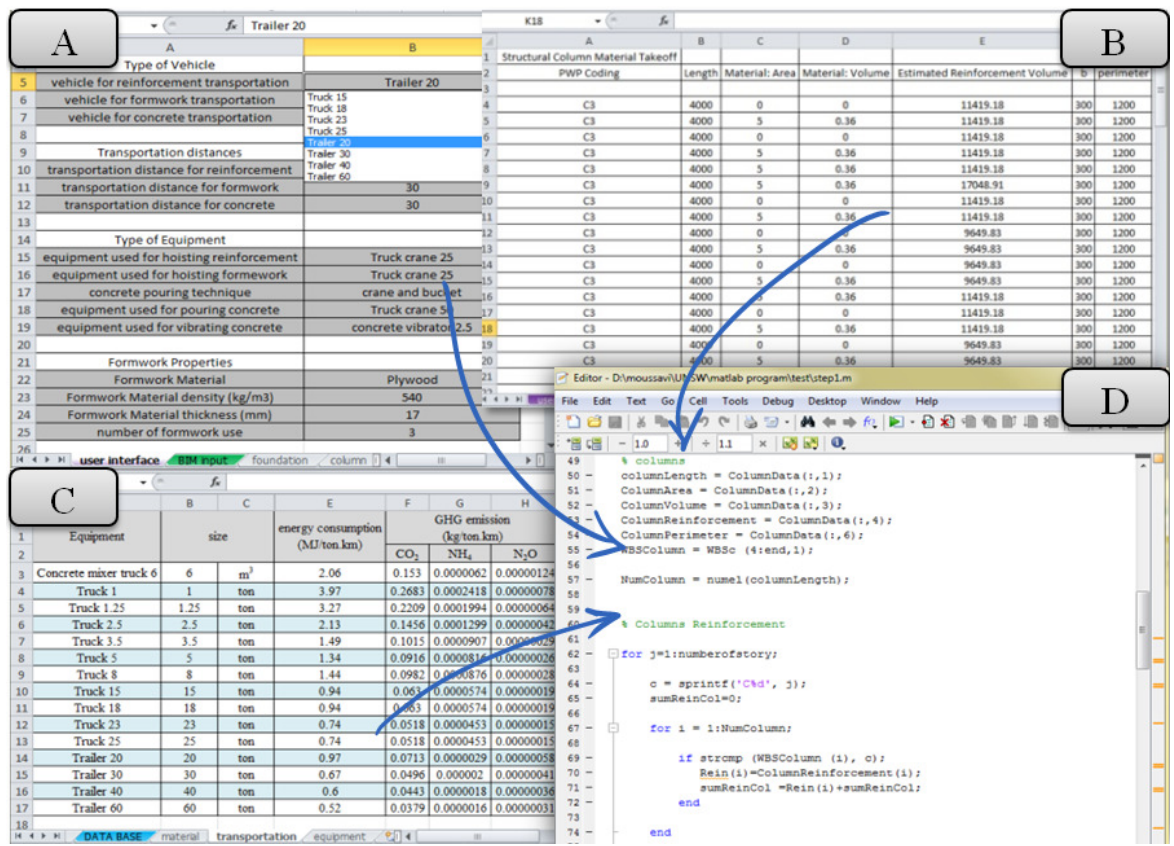

Figure 3. a, b) Project Database c) Carbon Database d) Construction process simulator

Table 2. Estimated carbon emissions

\begin{tabular}{lcccccc}
\hline \multicolumn{1}{c}{ Type of element } & Foundation & Column & Beam & Wall & Slab & sum \\
\hline Reinforcement (ton) & 1.29 & 4.80 & 8.61 & 7.82 & 9.89 & 32.41 \\
$\mathrm{CO}_{2}$ emissions from reinforcement transportation $(\mathrm{kg})$ & 4.14 & 15.42 & 27.61 & 25.08 & 31.73 & 103.98 \\
$\mathrm{CO}_{2}$ emissions from reinforcement hoisting $(\mathrm{kg})$ & 1.12 & 4.18 & 7.48 & 6.80 & 8.60 & 28.18 \\
Formwork $\left(\mathrm{m}^{2}\right)$ & 80.88 & 431.52 & 614.20 & 610.48 & 830.00 & 2567.08 \\
$\mathrm{CO}_{2}$ emission from formwork transportation $(\mathrm{kg})$ & 2.38 & 12.71 & 18.09 & 17.98 & 24.45 & 75.61 \\
$\mathrm{CO}$ emission from formwork material $(\mathrm{kg})$ & 87.08 & 464.60 & 661.29 & 657.28 & 893.63 & 2763.89 \\
$\mathrm{CO} 2$ emission from formwork hoisting $(\mathrm{kg})$ & 0.65 & 3.44 & 4.90 & 4.87 & 6.63 & 20.49 \\
$\mathrm{Concrete}\left(m^{3}\right)$ & 22.20 & 16.74 & 51.60 & 91.57 & 99.47 & 281.58 \\
$\mathrm{CO}_{2}$ emission from concrete transportation $(\mathrm{kg})$ & 652.15 & 491.75 & 1515.80 & 2689.96 & 2922.03 & 8271.69 \\
$\mathrm{CO}_{2}$ emission from concrete pouring $(\mathrm{kg})$ & 60.76 & 83.30 & 313.84 & 278.48 & 286.58 & 1022.97 \\
$\mathrm{CO}_{2}$ emission from concrete vibration $(\mathrm{kg})$ & 12.03 & 16.50 & 62.15 & 55.15 & 56.75 & 202.58 \\
\hline
\end{tabular}


It should be noted that in this study, only the emissions associated directly with construction of concrete structural elements were estimated. The unit emissions of the required equipment identified and selected are summarized in Table 3. The estimated $\mathrm{CO}_{2}$ emissions for construction of individual elements present in the building information model are summarized in Table 2.

Table 3. $\mathrm{CO}_{2}$ emission factor for different Vehicle/Equipment used in construction of the case structure [8]

\begin{tabular}{|c|c|c|}
\hline Usage & $\begin{array}{c}\text { Type of } \\
\text { Vehicle / } \\
\text { Equipment }\end{array}$ & $\begin{array}{c}\mathrm{CO}_{2} \\
\text { emission } \\
\text { factor }\end{array}$ \\
\hline $\begin{array}{l}\text { Vehicle for reinforcement } \\
\text { transportation }\end{array}$ & Trailer 20 & $\begin{array}{c}0.0713 \\
\text { (kg/ton. } \mathrm{km})\end{array}$ \\
\hline $\begin{array}{l}\text { Vehicle for formwork } \\
\text { transportation }\end{array}$ & Trailer 20 & $\begin{array}{c}0.0713 \\
(\mathrm{~kg} / \text { ton. } \mathrm{km})\end{array}$ \\
\hline $\begin{array}{l}\text { Vehicle for concrete } \\
\text { transportation }\end{array}$ & $\begin{array}{c}\text { Concrete mixer } \\
\text { truck } 6\end{array}$ & $\begin{array}{c}0.153 \\
\text { (kg/ton.km) }\end{array}$ \\
\hline $\begin{array}{l}\text { Equipment used for hoisting } \\
\text { reinforcement }\end{array}$ & Truck crane 25 & $\begin{array}{l}15.956 \\
(\mathrm{~kg} / \mathrm{hr})\end{array}$ \\
\hline $\begin{array}{l}\text { Equipment used for hoisting } \\
\text { formework }\end{array}$ & Truck crane 25 & $\begin{array}{l}15.956 \\
(\mathrm{~kg} / \mathrm{hr})\end{array}$ \\
\hline $\begin{array}{l}\text { Equipment used for pouring } \\
\text { concrete }\end{array}$ & Truck crane 50 & $\begin{array}{l}26.157 \\
(\mathrm{~kg} / \mathrm{hr})\end{array}$ \\
\hline $\begin{array}{l}\text { Equipment used for vibrating } \\
\text { concrete }\end{array}$ & $\begin{array}{c}\text { Concrete } \\
\text { vibrator } 2.5\end{array}$ & $\begin{array}{c}2.59 \\
(\mathrm{~kg} / \mathrm{hr})\end{array}$ \\
\hline
\end{tabular}

Figure 4a shows the breakdown of the relative proportions of $\mathrm{CO}_{2}$ emissions corresponding to the transportation of materials, operation of on-site equipment and the embodied carbon of the temporary materials used. As shown, transportation was identified as the largest contributor to the carbon emissions incurred in the construction phase, accounting for $67.7 \%$ of the total construction emissions estimated. This is while the assumed average distance of $30 \mathrm{~km}$ between the material processing/production plants and construction site is an optimistic assumption and may be exceeded in many actual construction projects.

The objective of the case study presented here is solely to illustrate the advantages of the method illustrated in this paper. In addition, due to the sensitivity of emission estimates to the project specific parameters, the results presented here cannot be used as indicators of average contribution of various parameters to the overall construction emissions. However, by taking into account the reasonable or even optimistically short (in some cases) travelling distances considered for materials transportation, the relatively high transportation emissions observed for the case project highlights the importance of considering the contribution of transportation in estimating the carbon emissions of construction. It should be noted that the material embodied carbon values reported by the majority of inventories available are cradle to gate values and therefore do not account for transportation emissions.

The results presented in Figure 4 show that temporary materials used for formworks are the second contributor to the construction carbon emissions, accounting for about $22.1 \%$ of the total construction emissions. The contribution of temporary materials to construction emissions may vary significantly depending on the type of the formwork material used and number of times the formworks are reused. Results showed that the contribution of construction operations to construction carbon emissions is smaller than that of transportation and temporary materials. As shown, construction operations were estimated to account for about only $10.2 \%$ of the construction emissions incurred. Figure $4 \mathrm{~b}$ illustrates the contribution of different elements to the carbon emissions of the construction stage. As shown, for the case project presented, slabs seem to be responsible for a higher amount of $\mathrm{CO}_{2}$ emission in the construction phase compared to the other considered.

The relatively high contributions of transportation and temporary materials to the construction emissions suggest that the local availability of materials and embodied carbon of temporary materials should be considered as two important parameters during the design and planning stage to reduce the construction emissions. As shown, the availability of a construction simulator and carbon estimation tool can be highly beneficial in early stages of building design by providing designers and construction managers with a tool to compare various design and construction plan alternatives.

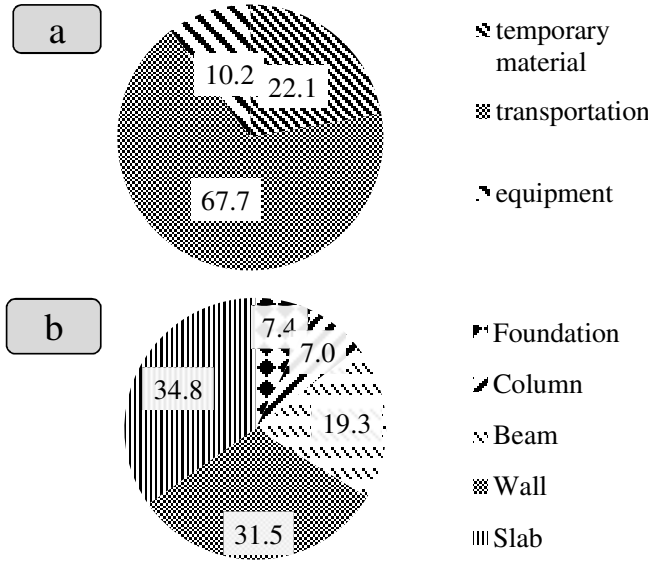

Figure 4. The contribution of different; a) parameters b) elements; in the carbon emission of the construction stage 


\section{Conclusion}

In this study, a computational framework was proposed to estimate the carbon emissions incurred in the construction phase at early stages of design and project planning when detailed construction plans and schedules are not available. The results of a case study were presented to illustrate the advantages of the method proposed. The proposed framework may be used to estimate the construction carbon emissions before the start of the actual construction process and therefore can be utilized by designers and construction managers to compare various design and construction plan alternatives.

\section{References}

[1] Intergovernmental Panel on Climate Change (IPCC), IPCC Fourth Assessment Report: Climate Change 2007 (AR4), Working Group I: The Physical Science Basis, 2007.

[2] United Nations Environment Programme (UNEP), Building and Climate Change: Summary for DecisionMakers, Sustainable Buildings \& Climate Initiative, pp. 62, 2009.

[3] Cole R.J. Energy and greenhouse gas emissions associated with the construction of alternative structural systems. Building and Environment, 34 (3):335-348, 1998.

[4] Guggemos A. A. and Horvath A. Decision-Support Tool for Assessing the Environmental Effects of Constructing Commercial Buildings. Journal of Architectural Engineering, 12 (4):187-195, 2006.

[5] Guggemos A. A. and Horvath A. Comparison of environmental effects of steel- and concrete-framed buildings. Journal of Infrastructure Systems, 11(2): 93$101,2005$.

[6] Yan H., Shen Q., Fan L.C.H., Wang Y. and Zhang L. Greenhouse gas emissions in building construction: A case study of One Peking in Hong Kong. Building and Environment, 45(2010): 949-955, 2010.

[7] Mao C., Shen Q., Shen L. and Tang L. Comparative study of greenhouse gas emissions between off-site prefabrication and conventional construction methods: Two case studies of residential projects. Energy and Buildings, 66 (2013): 165-176, 2013.

[8] Hong T., Ji C.Y., Jang M.H. and Park H.S. Assessment Model for Energy Consumption and Greenhouse Gas Emissions during the Construction Phase. Journal of Management in Engineering, 2013.
[9] K.W. Wong J. K.W., Li H., Wang H., Huang T., Luo E. and $\mathrm{Li} \mathrm{V}$. Toward low-carbon construction processes: the visualisation of predicted emission via virtual prototyping technology, Automation in Construction, 33 (2013): 72-78, 2013.

[10] Russell-Smith S., Lepech M. Dynamic Life Cycle Assessment of Building Design and Retrofit Processes. In Proceedings of the 2011 ASCE International Workshop on Computing in Civil Engineering, pages 760-767, Miami, Florida, 2011.

[11] RSMeans, Building Construction Cost Data, RSMeans a division of Reed Construction Data Construction Publishers \& Consultants, 700 Longwater Drive Norwell, MA 02061, USA, 2012.

[12] Hammond G. and Jones C. Embodied carbon: the inventory of carbon and energy (ICE), in: A BSRIA Guide, University of Bath and BSRIA, 2011.

[13] Andrew A. Embodied Energy and $\mathrm{CO}_{2}$ Coefficients for NZ Building Materials, Centre for Building Performance Research Report, 2003. 